\title{
Spatial uniformity in depth optima of midges: evidence from sedimentary archives of shallow Alpine and boreal lakes
}

\author{
Tomi P. LUOTO* \\ Department of Geosciences and Geography, University of Helsinki, P.O. Box 64, FI-00014 University of Helsinki \\ Secondary address: Institute for Limnology, Austrian Academy of Sciences, A-5310 Mondsee, Austria \\ *Corresponding author: tomi.luoto@helsinki.fi
}

\begin{abstract}
In this study, water depth optima, i.e. habitat preferences within a depth gradient, were estimated for mutual midge (Diptera: Nematocera; Ceratopogonidae, Chironomidae) taxa in surface sediment intralake data sets from eastern Finland and Austrian Alps and in a regional data set across Finland. The aim was to investigate how the optima and tolerances differ in these data sets and to discuss whether the possible causal factor for deviance is related to local adaptation, taxa representativeness, or some other factor. A total of 20 mutual taxa were found from the data sets and the estimated optima and tolerances were highly similar, with the exception of three taxa, which had deviating optima in the Austrian lake. The reason for these differences was most likely that the optima were poorly estimated in the Austrian lake due to low abundances and number of occurrences of these taxa. No evidence for intraspecific niche separation or local habitat adaptation was found between the Austrian and Finnish sites, although, interspecific variation in habitats was evident. Therefore, water depth optima estimated from representative number of specimens may be applicable for various ecological, limnological, and paleolimnological purposes. However, when the optima are applied outside the data set's coverage, the results should be interpreted with caution. In addition, the given optima are not applicable in sites deeper than the sites in the data sets.
\end{abstract}

Key words: autecology, Chironomidae, habitats, fossil remains, paleolimnology, water depth.

Received: October 2011. Accepted: November 2011.

\section{INTRODUCTION}

Water depth is an important regulator of the distribution of aquatic insects, including midge (Diptera: Nematocera) larvae (Mousavi 2002). The influence of water depth is mostly indirect and mediated through habitat distribution, such as availability of macrophytes and the type of substrate, which have been found to be of direct importance for midges (Learner et al. 1989; Nyman et al. 2005). Fossil remains of midges, mostly Chironomidae, usually accumulate close to their living habitats (Eggermont et al. 2007; Kurek, and Cwynar 2009a; Luoto 2010, 2011; Engels, and Cwynar 2011). Hence, it is possible to use these fossil assemblages to infer past changes in their habitats from downcore sediment profiles. Because the habitats are directly related to water depth, the fossil assemblages can further be used as proxies for lake level changes (Korhola et al. 2000, Barley et al. 2006; Luoto 2009a). Importantly, lake levels are sensitive indicators of changes in the relationship between precipitation and evapotranspiration, i.e. effective precipitation. Therefore, paleolimnological records of midges can be used to fulfill the lack of long-term monitoring data of paleoprecipitation (Luoto et al. 2010; Luoto, and Sarmaja-Korjonen 2011) that at best is fragmentary and spatially restricted.

In paleolimnology, chironomids are most often used as proxies for temperature dynamics (Brooks 2006; Egger- mont, and Heiri 2011), whereas in contemporary biomonitoring they have been found useful in characterizing the limnological and ecological status of their environment (Raunio et al. 2010; Ruse 2010, 2011). However, lake morphometric features, most importantly water depth, can have major influence on the chironomid-based contemporary estimates (Jyväsjärvi et al. 2009) but also on paleotemperature inferences if lake level would be to change in time (Luoto 2010). Although the influence of water depth on chironomid distribution is indisputable, little knowledge is available for the preferences of individual taxa and even less on the geographical differences between the taxa optima. This knowledge would have relevance for example when considering the suitability of a paleolimnological midge-based water depth inference model outside the training set area.

Previous studies have shown that the influence of water depth on midge distribution can be detected from lake surface sediment data of fossils collected using site-specific (intralake), local, and regional data sets (Korhola et al. 2000; Kurek, and Cwynar 2009b; Luoto 2009a, 2010; Engels, and Cwynar 2011). Kurek and Cwynar (2009b) showed significant differences in the performance statistics of North American site-specific, local, and regional training sets implying differences in taxa optima through spatial scales. In this study, intra-lake data sets from the Austrian Alps and eastern Finland and a multilake regional data set from Fin- 
land are compared aiming to disentangle whether the taxa differ in their water depth optima and tolerances. An aim is also to examine how strongly the optima are deviated among the rare taxa. The hypothesis of this study is that the water depth gradients reflect habitat types, including submerged vegetation, substrate type, and physical and chemical properties, and hence, when estimating a depth optimum for a taxon, also its habitat is estimated. The present results can be useful in understanding midge habitat ecology and in paleolimnological applications and biomonitoring.

\section{MATERIALS AND METHODS}

The study sites are located in the Austrian Alps $\left(47^{\circ} \mathrm{N}\right.$, $\left.14^{\circ} \mathrm{E}\right)$ and Finland $\left(60-70^{\circ} \mathrm{N}, 22-30^{\circ} \mathrm{E}\right)$ and consist of two site-specific intralake data sets and one regional multilake dataset. Lake Moaralmsee is located in the Niedere Tauern in the eastern Austrian Alps at an altitude of $1825 \mathrm{~m}$ a.s.l. The lake is oligotrophic and without distinct macrophyte growth. 31 surface sediment samples (topmost 0-1 cm) were collected from Moaralmsee along the water depth gradient (0.1-7.2 m). Lake Pieni-Kauro is a dystrophic basin located in eastern Finland at an elevation of $188 \mathrm{~m}$ a.s.1. and it has a variety of habitats for midge species. A total of 34 surface sediment samples (topmost $0-1 \mathrm{~cm}$ ) were collected along the depth gradient $(0.5-7.3 \mathrm{~m})$ from the lake and its inlet at different depths but only the 31 lentic samples were used in this study after removal of the lotic sites to reduce extraneous noise. The regional multilake data set of single surface sediment samples (topmost $0-1 \mathrm{~cm}$ ) from various depths $(0.7-7.0 \mathrm{~m})$ covers the whole latitudinal transect of Finland with a variety of lake types. Lake Pieni-Kauro is not included among the 84 regional lakes. This study involves very different lake types but the data sets have similar depth range. Detailed site and sample descriptions together with the community compositions are provided elsewhere (Luoto 2009b, 2010, 2011; Luoto, and Helama 2010).

Taxa optima and tolerances were estimated using weighted averaging. This method is suitable for the present data due to the similar depth gradients between the data sets. The optima and tolerance calculations were performed on relative abundance data considering the whole midge community within a sample, although only the mutual taxa are discussed in this paper. Representativeness of a taxon in a data set was assed using the Hill's (1973) N2 diversity index (effective number of occurrences) with a cut-off value of 5 (cf. Brooks, and Birks 2001).

\section{RESULTS AND DISCUSSION}

From the three data sets, 20 mutual midge taxa were found, of which 2 were Ceratopogonidae and 18 Chironomidae. 13 taxa in Moaralmsee, 3 in Pieni-Kauro, and 4 in the regional data set had N2 diversity index $<5$. In all, 7 (Chironomus anthracinus-type, Corynoneura lobata-type,
Dasyhelea-type, Limnophyes, Micropsectra contractatype, $M$. radialis-type, and Tanytarsus pallidicornis-type) of the 20 examined taxa in Moaralmsee had $<2$ occurrences and maximum abundance of $<2 \%$, whereas in Pieni-Kauro 1 (M. contracta-type) and in the regional data set 2 (Pseudosmittia and Synorthocladius) taxa did not reach these levels.

Previous results have shown that the distribution of midge taxa is strongly influenced by water depth in the shallow lakes of the present data sets (Luoto 2009a, 2010, 2011). In general, the calculated water depth optima of midge taxa showed closely similar patterns with the taxa tolerances in range (Fig. 1). Consistent patterns were detected between the littoral (Bezzia-type and Dasyheleatype ceratopogonids, Corynoneura arctica-type, Psectrocladius sordidellus-type, and Cricotopus intersectus-type), sublittoral (e.g., Heterotrissocladius marcidustype, Paratanytarsus austriacus-type, and Procladius), and deeper water (Tanytarsus lugens-type, Sergentia, Micropsectra contracta-type, and $M$. radialis-type) taxa. However, three distinctly diverging optima were found belonging to Corynoneura lobata-type, Chironomus anthracinus-type, and Tanytarsus pallidicornis-type. In all these cases, the divergence was in the optima estimated from Moaralmsee, whereas the optima between PieniKauro and the regional data set were very close. Interestingly, all these taxa suffered from low occurrences and abundances in Moaralmsee and had N2 $<5$. Therefore, in the case of C. lobata-type, C. anthracinus-type, and T. pallidicornis-type, it is likely that the water depth optima in Moaralmsee are biased due to their under-representativeness. It is also possible, that there is local adaptation involved behind the estimates due to the remoteness of the sites and it may also be that the species involved are not the same because the fossils of these taxa can be identified only to species-type level, which can consist of two or more species. However, it is likely that similar morphotypes are associated with similar lifestyles and moreover, life-styles are closely connected to habitats and hence, indirectly, to water depth. Previous studies have shown that C. lobata occurs in the littoral (Boggero et al. 2006) and Chironomus and Tanytarsus species are commonly found from shallow to profundal areas (Mousavi 2002), thus, having intermediate optima and wide tolerances. Therefore, it is not totally surprising that the optima of these taxa in Moaralmsee showed shallow/deep preference based on a low number of specimens. It is also worth to notice that if the depth gradients were to be enlarged, the optima of the deeper water taxa would likely become deeper and their tolerances would become larger. Therefore, the present results cannot be straightforwardly applied to sites deeper than the deep-est sites in the data sets.

In addition to the three taxa mentioned above, only the tolerance of $M$. radialis-type in the regional data set was 


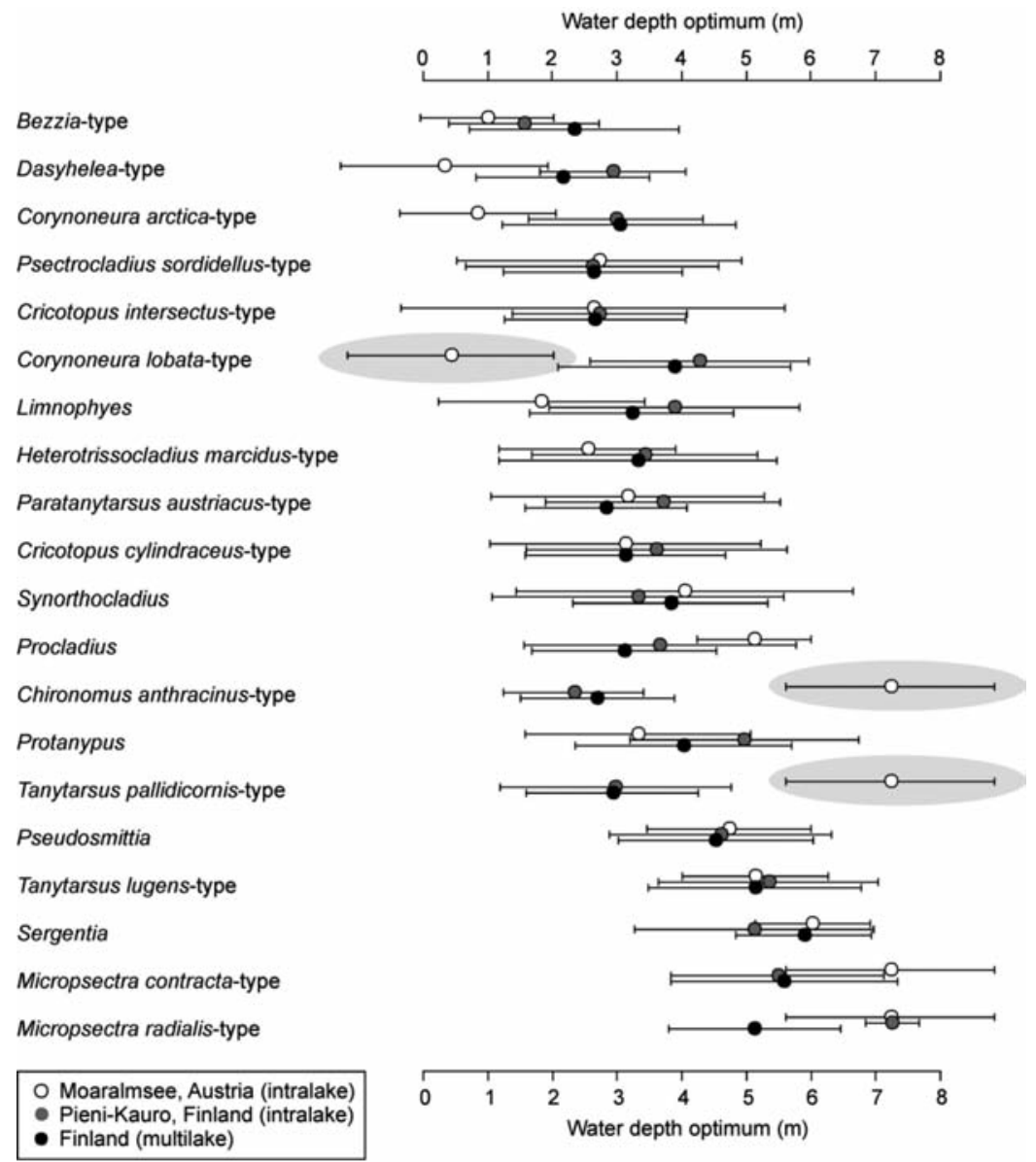

Fig. 1. Optima and tolerances (assessed using weighted averaging) of mutual midge taxa in lakes Moaralmsee in the Austrian Alps and Pieni-Kauro in eastern Finland and in the regional data set from Finland. The deviating taxa optima are marked with gray ellipses.

not in the range of its tolerance in Pieni-Kauro. However, the optimum was parallel between the two intralake data sets. It is noteworthy that $M$. radialis-type was a rare taxon in all of the data sets, yet, the optima showing deep water preference in all of them. As also other studies have identified $M$. radialis-type as a taxon dominating in the profundal zone (Tátosová, and Stuchlík 2006), it appears that only the estimated tolerance in Pieni-Kauro is too narrow. The narrow tolerance in Pieni-Kauro is due to $M$. $r a-$ dialis-type occurring only in two of the deepest samples, with its maximum in the deepest sample (Luoto 2010). Despite, the narrow tolerance of $M$. radialis-type in PieniKauro, the Finnish midge water depth preferences were noticeably similar providing evidence that the depth optima can be resolved reliably using both intra- and multilake data sets of fossil midges in surface sediment samples. It is also intriguing that similar water depth optima can be distinguished from very different lake types.

Spatial autocorrelation, which is a common feature in all spatially structured ecological data (Legendre 1993), can potentially cause problems in estimating reliable taxa optima. In spatial autocorrelation, the neighboring samples have a strong tendency to resemble one another. The fact that the present results showed generally very close estimates between the taxa optima in the two remote intralake data sets and in the regional data set suggests that the taxa optima in the surface sediment data sets are not significantly biased by spatial autocorrelation. It is very unlikely that such autocorrelation would exists that could cause similar autocorrelation patterns in these very different (intra- vs multilake, Alpine $v s$ boreal lakes) data sets. In particular, Tanytarsus lugens-type suffered the most from autocorrelation in Moaralmsee, but the present results demonstrate that its optimum and tolerance are indeed extremely similar also in the Finnish intra- and multilake datasets further suggesting that spatial autocorrelation is not a major concern in these data sets.

\section{CONCLUSIONS}

The present results indicate strong spatial uniformity in midge water depth optima and tolerances across different special scales and geographical areas from the low el- 
evation northern boreal and subarctic lakes to high elevation Alpine lakes. It is likely that the habitat ecology of the examined taxa is very similar in the present data sets and no intraspecific niche separation or local adaptation seems to occur, although, interspecific variability in taxa optima extends to the whole examined water depth gradient. The few differences in the estimated taxa optima were possibly results of low number of specimens, and hence, consequences of the bias in the estimated optima. Therefore, if midge taxa optima and tolerances are estimated based on a representative number of specimens, the estimations should be reliable and applicable in various ecological, limnological, and paleolimnological applications. However, it should be noted that the present taxa preferences are strictly valid only in the data set lakes themselves and if applied to sites outside the data sets' geographical coverage, they should be considered with caution. Furthermore, the optima given in this study are valid only in shallow sites.

\section{ACKNOWLEDGMENTS}

The data sets used in this study were collected during the DETECTIVE (DEcadal deTECTion of biodIVErsity in alpine lakes, Austrian Academy of Sciences), EPHIPPIUM (Academy of Finland, grant no. 1107062), and INFER (INtralake Fossil invERtebrate Assemblages, the Finnish Entomological Society) projects. Personal funding to perform this study was provided by the Kone Foundation and Academy of Finland (project no. 250343). I thank Dr Liisa Nevalainen for useful suggestions and comments on an early version of the manuscript and the two anonymous reviewers for their constructive criticism.

\section{REFERENCES}

Barley EM, Walker IR, Kurek J, Cwynar LC, Mathewes RW, Gajewski K, and Finney BP. 2006. A northwest North American training set: distribution of freshwater midges in relation to air temperature and lake depth. J. Paleolimnol. 36: 295-314.

Boggero A, Füreder L, Lencioni V, Simcic T, Thaler B, Ferrarese U, Lotter AF, and Ettinger R. 2006. Littoral chironomid communities of Alpine lakes in relation to environmental factors. Hydrobiologia 562:145-165.

Brooks SJ. 2006. Fossil midges (Diptera: Chironomidae) as palaeoclimatic indicators for the Eurasian region. Quat. Sci. Rev. 25: 1894-1910.

Brooks SJ, and Birks HJB. 2001. Chironomid-inferred air temperatures from Lateglacial and Holocene sites in Northwest Europe: progress and problems. Quat. Sci. Rev. 20: 17231741.

Eggermont H, and Heiri O. 2011. The chironomid-temperature relationship: expression in nature and palaeoenvironmental implications. Biol. Rev. DOI: 10.1111/j.1469-185X.2011. 00206.x.

Eggermont H, De Deyne P, and Verschuren D. 2007. Spatial variability of chironomid death assemblages in the surface sediments of a fluctuating tropical lake (Lake Naivasha, Kenya). J. Paleolimnol. 38: 309-328.

Engels S, and Cwynar LC. 2011. Changes in fossil chironomid remains along a depth gradient: evidence for common faunal breakpoints within lakes. Hydrobiologia 665: 15-38.

Hill MO. 1973. Diversity and evenness: a unifying notation and its consequences. Ecology 54: 427-432.

Jyväsjärvi J, Tolonen KT, and Hämäläinen H. 2009. Natural variation of profundal macroinvertebrate communities in boreal lakes is related to lake morphometry: implications for bioassessment. Can. J. Fish. Aquat. Sci. 66: 589-601.

Korhola A, Olander H, and Blom T. 2000. Cladoceran and chironomid assemblages as quantitative indicators of water depth in subarctic Fennoscandian lakes. J. Paleolimnol 24: 43-53.

Kurek J, and Cwynar LC. 2009a. Effects of within-lake gradients on the distribution of fossil chironomids from maar lakes in western Alaska: implications for environmental reconstructions. Hydrobiologia 623: 37-52.

Kurek J, and Cwynar LC. 2009b. The potential of site-specific and local chironomid-based inference models for reconstructing past lake levels. J. Paleolimnol. 42: 37-50.

Learner MA, Wiles PR, and Pickering JG. 1989. The influence of aquatic macrophyte identity on the composition of the chironomid fauna in a former gravel pit in Berkshire, England. Aquat. Insect. 11: 183-191.

Legendre P. 1993. Spatial autocorrelation: trouble or new paradigm? Ecology 74: 1659-1673.

Luoto TP. 2009a. A Finnish chironomid- and chaoborid-based inference model for reconstructing past lake levels. Quat. Sci. Rev. 28: 1481-1489.

Luoto TP. 2009b. Subfossil Chironomidae (Insecta: Diptera) along a latitudinal gradient in Finland: development of a new temperature inference model. J. Quat. Sci. 24: 150-158.

Luoto TP. 2010. Hydrological change in lakes inferred from midge assemblages through use of an intralake calibration set. Ecol. Monogr. 80: 303-329.

Luoto TP. 2011. Intra-lake patterns of aquatic insect and mite remains. J. Paleolimnol. DOI: 10.1007/s10933-011-9565-2.

Luoto TP, and Helama S. 2010. Palaeoclimatological and palaeolimnological records from fossil midges and treerings: the role of the North Atlantic Oscillation in eastern Finland through the Medieval Climate Anomaly and Little Ice Age. Quat. Sci. Rev. 29: 2411-2423.

Luoto TP, and Sarmaja-Korjonen K. 2011. Midge-inferred Holocene effective moisture fluctuations in a subarctic lake, northern Lapland. Boreas 40: 650-659.

Luoto TP, Kultti S, Nevalainen L, and Sarmaja-Korjonen K. 2010. Temperature and effective moisture variability in southern Finland during the Holocene quantified with midge-based calibration models. J. Quat. Sci. 25: 13171326.

Mousavi SK. 2002. Boreal chironomid communities and their relation to environmental factors - the impact of lake depth, size and acidity. Boreal Env. Res. 7: 63-75.

Nyman M, Korhola A, and Brooks SJ. 2005. The distribution and diversity of Chironomidae (Insecta: Diptera) in western Finnish Lapland, with special emphasis on shallow lakes. Global Ecol. Biogeogr. 14: 137-153. 
Raunio J, Paasivirta L, and Hämäläinen H. 2010. Assessing lake trophic status using spring-emerging chironomid pupal exuviae. Fundam. Appl. Limnol. (Arch. Hydrobiol.) 176: 61-73.

Ruse L. 2010. Classification of nutrient impact on lakes using the chironomid pupal exuvial technique. Ecol. Indic. 10: 594-601.
Ruse L. 2010. Lake acidification assessed using chironomid pupal exuviae. Fundam. Appl. Limnol. 178: 267-286.

Tátosová J, and Stuchlík E. 2006. Seasonal dynamics of chironomids in the profundal zone of a mountain lake (Ladové pleso, the Tatra Mountains, Slovakia). Biologia, Bratislava, 61/Suppl. 18: 203-212. 